\title{
Studies on Fumarase
}

\section{THE EFFECT OF TEMPERATURE}

\author{
By V. MASSEY \\ Sir William Dunn Institute of Biochemistry, University of Cambridge
}

(Received 8 March 1952)

A study of the variation with temperature and $\mathrm{pH}$ of such properties of an enzyme as its maximum velocity and affinities for substrates and inhibitors might be expected to throw valuable light on the mechanism of the reaction catalysed by the enzyme. In this paper are reported some results on the variation of maximum velocity and Michaelis constants with temperature of crystalline fumarase, as well as the variation of Michaelis constants with $\mathrm{pH}$. The variation of activity with $\mathrm{pH}$ in the presence of various salts has already been reported (Massey, 1952), and the variation of inhibitory constants of a number of dicarboxylic acids with both temperature and $\mathrm{pH}$ will be reported in a future paper.

\section{METHODS}

Fumarase. The fumarase solutions used were of twice recrystallized material obtained from pigs' hearts as already described (Massey, 1952).

Estimation of enzyme activity. Details are given in the second paper of this series (Massey, 1953). All the values reported here are initial velocities, when the reaction rate is still constant.

Activating anions. All the experiments reported here, unless stated to the contrary, were carried out in the presence of $0.067 \mathrm{M}$-phosphate buffers.

Temperature control. The temperature was controlled to within $\pm 0 \cdot 1^{\circ}$ of the desired temperature by means of an apparatus designed by Dr M. Dixon, F.R.S., which will be described in a separate communication.

Determination of the ionization constants of fumaric acid. These were determined by electrometric titration of $0.02 \mathrm{M}$ fumaric acid with $\mathrm{CO}_{2}$-free $0 \cdot 025 \mathrm{~N}-\mathrm{NaOH}$. The temperature was maintained constant to within $\pm 0 \cdot 1^{\circ}$ by immersion in a thermostated water bath. Stirring of the reaction mixture was accomplished by a constant stream of $\mathrm{CO}_{2}$-free $\mathrm{N}_{2}$, to prevent the absorption of $\mathrm{CO}_{2}$ from the atmosphere into the reaction mixture. The titration was followed by measuring the $\mathrm{pH}$ with a 'Cambridge' electrometer, the power for which was supplied by a $12 \mathrm{~V}$. storage battery. The instrument was standardized at the particular temperature investigated with $0.05 \mathrm{M}$-potassium hydrogen. phthalate buffer, the $\mathrm{pH}$ value of which was taken to be 4.00 at all the temperatures investigated. The instrument was checked for drift at the end of the titration; only in those cases where the drift was less than $\pm 0.05 \mathrm{pH}$ unit were $\mathrm{pK}$ values calculated from the results.

The $\mathrm{pK}$ values reported here were calculated from the $\mathrm{pH}$ values of the mid points of the integral sections of the titration curve (see Britton, 1942).
Determination of Michaelis constants. Michaelis constants $\left(K_{m}\right)$ were determined by the method of Lineweaver \& Burk (1934).

\section{RESULTS}

The temperature coefficient of fumarate absorption. The absorption of fumarate in the ultraviolet is quite markedly temperature dependent. Fig. 1

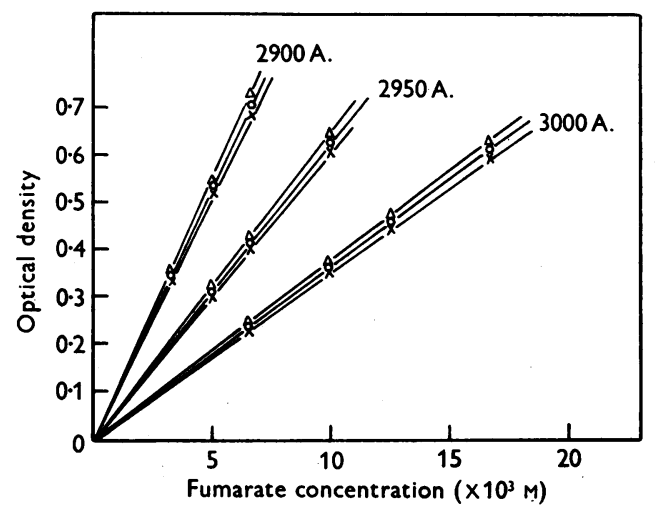

Fig. 1. The variation of optical density of sodium fumarate at $\mathrm{pH} 7.0$ with temperature. $\Delta, 40^{\circ} ; \bigcirc, 30^{\circ} ; \times, 20^{\circ}$. Thickness of cell $1 \mathrm{~cm}$.

shows the effect of temperature on the absorption of fumarate at several wavelengths. The proportionate increase in absorption with temperature at these wavelengths seems to be independent of the fumarate concentration; it amounts to a $3.5 \%$ increase in optical density, per $10^{\circ}$ rise in temperature. The absorption of fumarate seems to be independent of $\mathrm{pH}$ over the range $\mathrm{pH} \mathbf{5 \cdot 5}$ to $\mathrm{pH} 9$; below $\mathrm{pH} \mathbf{5}$, however, the absorption increases, this being due probably to the partially ionized form of the acid.

The extent of variation of the absorption of fumarate with temperature is insufficient to warrant correction values being applied to all results obtained. Accordingly, the experimental points in the graphs shown here have not been corrected for change in absorption with temperature. However, a correction factor has been applied to all calculations based on these graphs.

The effect of $\mathrm{pH}$ on the Michaelis constants. Fig. 2 shows the effect on the Michaelis constants, $K_{m}$, of 
altering the $\mathrm{pH}$. The $K_{m}$ for fumarate is much more $\mathrm{pH}$-sensitive than that for L-malate, but for both a definite maximum is reached at a particular $\mathrm{pH}$. These maxima, for both substrates, occur at approximately the same $\mathrm{pH}$ values as the optimal activities under the same conditions. Thus the $\mathrm{pH}$ optimum of fumarase in the presence of $0.067 \mathrm{M}$ phosphate with fumarate as substrate is $\mathrm{pH} \mathrm{6.95}$ (Massey, 1953); the pH of maximum $K_{m}$ is about 7.0. Similarly, the optimal activity under the same conditions, but with L-malate as substrate, is about $\mathrm{pH} 7 \cdot 7$, and from Fig. 2, the $\mathrm{pH}$ of maximum $K_{m}$ for

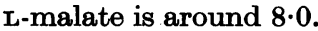

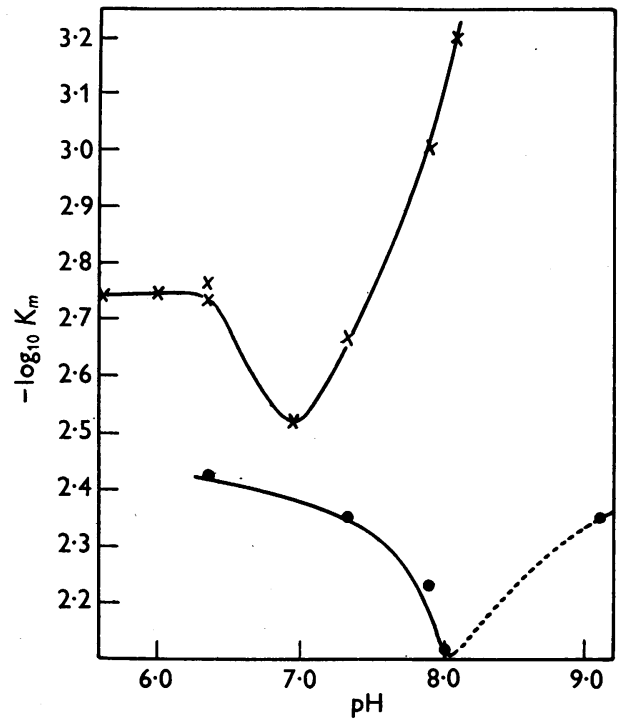

Fig. 2. The variation of Michaelis constants of fumarase with $\mathrm{pH}$ at $23^{\circ}$. $-\times-\times-$, fumarate as substrate; -O- malate as substrate.

The effect of temperature on reaction velocity. Fig. 3 shows the effect of temperature on the initial rate of conversion of L-malate to fumarate at various $\mathrm{pH}$ values when the initial concentration of L-malate was $0.033 \mathrm{M}$. The slopes shown are with different quantities of enzyme for the different $\mathrm{pH}$ values used in order to keep the velocities at convenient levels. These results show a high temperature coefficient indicating a high energy of activation as obtained from the Arrhenius equation. There is very little change in the energy of activation over the $\mathrm{pH}$ range studied, varying from $13100 \mathrm{cal}$. at $\mathrm{pH} \mathrm{7.94}$; through $14000 \mathrm{cal}$. at pH $7 \cdot 52$ to 15600 cal. at $\mathrm{pH} 6 \cdot 35$.

Figs. 4-6 show the effect of temperature in different $\mathrm{pH}$ ranges when the substrate is $0.0167 \mathrm{M}$ fumarate. As with the values for L-malate, these results are with different quantities of enzyme.
Similar slopes are obtained if the fumarate concentration is doubled. The effect of temperature when fumarate is substrate is of three different types. At high $\mathrm{pH}$ values results of the type shown in Fig. 4 are obtained, in which the activation energy at first remains constant as the temperature is increased, to change sharply at a particular temperature to a higher activation energy. At $\mathrm{pH}$ values around the optimum no change occurs in activation energy over the whole range of temperature investigated (Fig. 5). At low $\mathrm{pH}$ values (Fig. 6), the converse of what happens at high $\mathrm{pH}$ values occurs. Here, however, the temperature of changeover from one

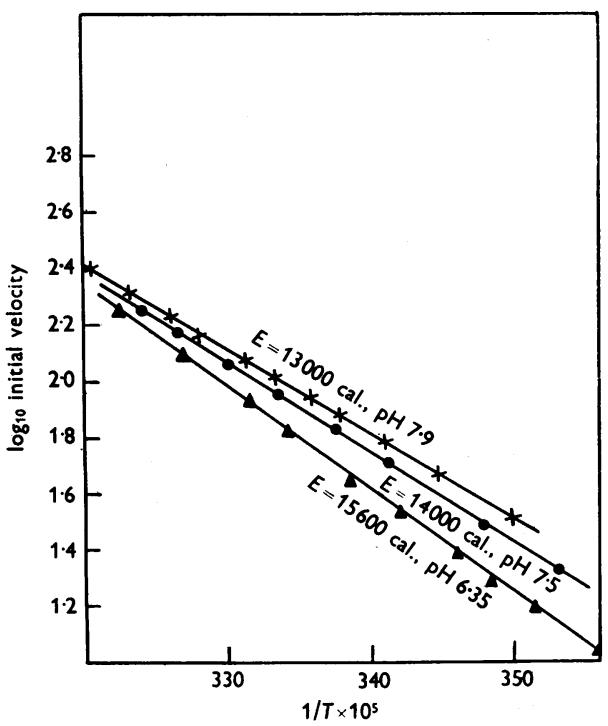

Fig. 3. The variation of the initial velocity of dehydration reaction of fumarase with temperature. Sodium L-malate concentration, $0.033 \mathrm{M}$.

activation energy to the other seems to be independent of $\mathrm{pH}$, occurring in the range $17-19^{\circ}$. Changes of the type shown in Fig. 6 have been found in the last few years with several enzymes (see reviews by Stearn, 1949; Sizer, 1943), but no temperature effects of the type shown in Fig. 4 have been found previously with any enzyme.

The values for the activation energies calculated from these graphs are shown in Table 1, and on the graphs themselves.

The changeover from a lower to a higher activation energy with increase in temperature is also shown with $\mathrm{L}$-malate as substrate at very high $\mathrm{pH}$ values. Fig. 7 shows the effect of temperature on the dehydration of L-malate at $\mathrm{pH} \mathrm{9.0} \mathrm{in} \mathrm{the}$ presence of $0.187 \mathrm{M}$-borate. Here the critical temperature is at $32^{\circ}$ and the activation energies below and above this temperature are 9300 and $14800 \mathrm{cal}$. 
However, no indication has ever been obtained of L-malate behaving in the same way as fumarate at lower $\mathrm{pH}$ values, where the opposite effect occurs.

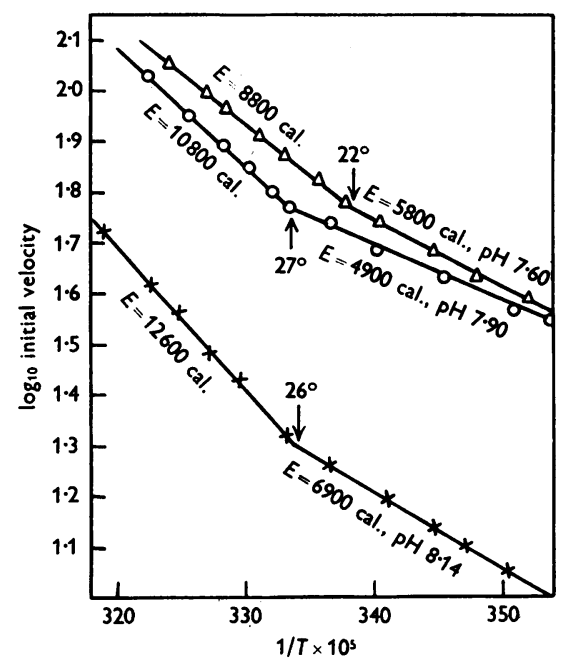

Fig. 4. The variation with temperature of the initial velocity of the hydration reaction of fumarase at alkaline $\mathrm{pH}$ values. Sodium fumarate concentration, $0.0167 \mathrm{M}$.

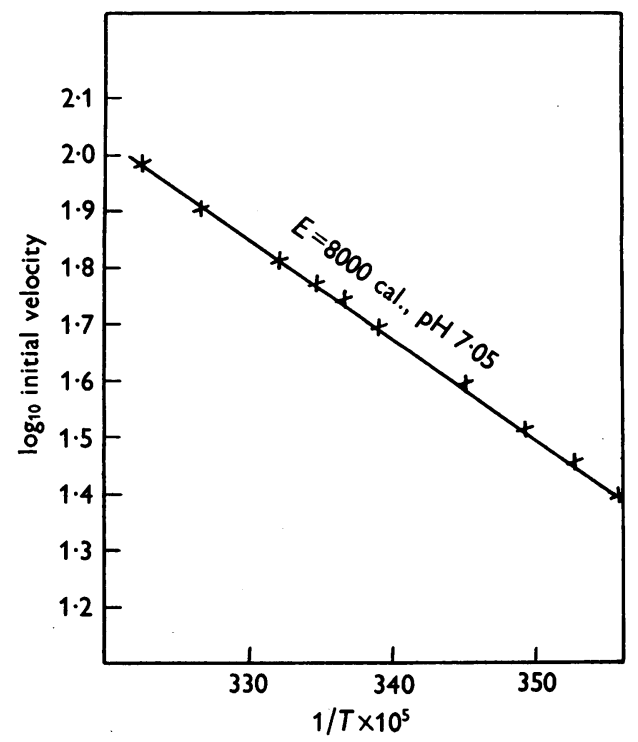

Fig. 5. The variation with temperature of the initial velocity of the hydration reaction of fumarase at $\mathrm{pH} 7$. Sodium fumarate concentration, $0.0167 \mathrm{~m}$.

The fact that the behaviour with fumarate and $\mathrm{L}$-malate is so different at low $\mathrm{pH}$ values suggests that under these conditions the concentration of water in a form capable of taking part in the reaction may be limiting over a certain temperature range. For example, it is possible that heavily hydrogen-bonded water may be incapable of orientation on the enzyme protein molecule in the way necessary for the hydration reaction to proceed. The breakage of hydrogen bonding in liquid

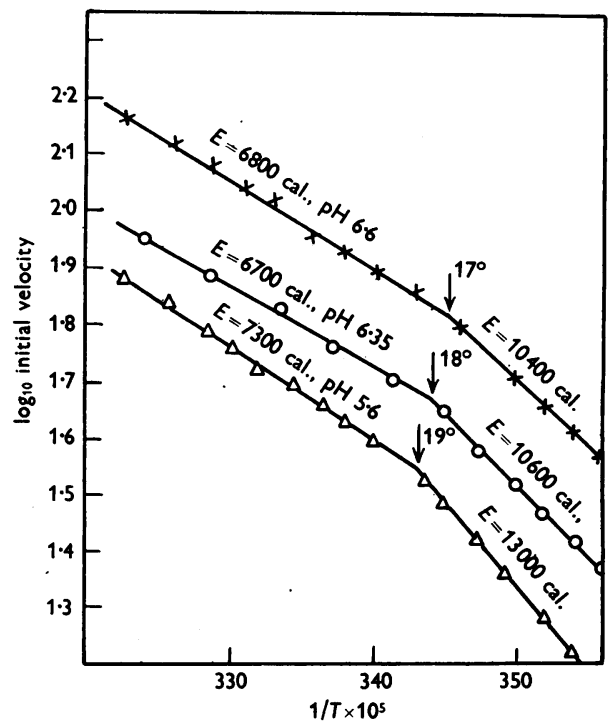

Fig. 6. The variation with temperature of the initial velocity of the hydration reaction of fumarase at acid $\mathrm{pH}$ values. Sodium fumarate concentration, $0.0167 \mathrm{M}$.

Table 1. The variation of activation energy of fumarase with temperature and $\mathrm{pH}$ with fumarate as substrate

$\begin{array}{lccc}\text { Activation } & \begin{array}{c}\text { Activation } \\ \text { energy at } \\ \text { lower temp. } \\ \text { (cal.) }\end{array} & \begin{array}{c}\text { energy at } \\ \text { higher temp. } \\ \text { (cal.) }\end{array} & \begin{array}{c}\text { Critical } \\ \text { temp. } \\ \text { pH }\end{array} \\ \begin{array}{c}{ }^{\circ} \text { ) } \\ 8 \cdot 14\end{array} & 6900 & 12600 & 26 \\ 7 \cdot 9 & 4900 & 10800 & 27 \\ 7 \cdot 6 & 5800 & 8800 & 22 \\ 7 \cdot 05 & 8000 & 8000 & \text { None } \\ 6 \cdot 6 & 10400 & 6800 & 17 \\ 6 \cdot 35 & 10600 & 6700 & 18 \\ 5 \cdot 6 & 13000 & 7300 & 19 \\ 5 \cdot 3 & 13700 & - & -\end{array}$

water increases rapidly with temperature; it is possible that at low temperatures sufficient hydrogen bonding exists to prevent the reaction proceeding at the maximum rate. If such a premise were true, the addition of substances capable of breaking the hydrogen bonds between water molecules, should abolish the change from one activation energy to another, or should at least lower the temperature at which such a break normally occurs. Methanol and ethanol are known to be capable of such an action. Fig. 8 shows the effect of $10 \%$ methanol on the temperature coefficients with 
fumarate as substrate. The effect of methanol is to abolish the changes in activation energy already mentioned, and at the same time to increase the

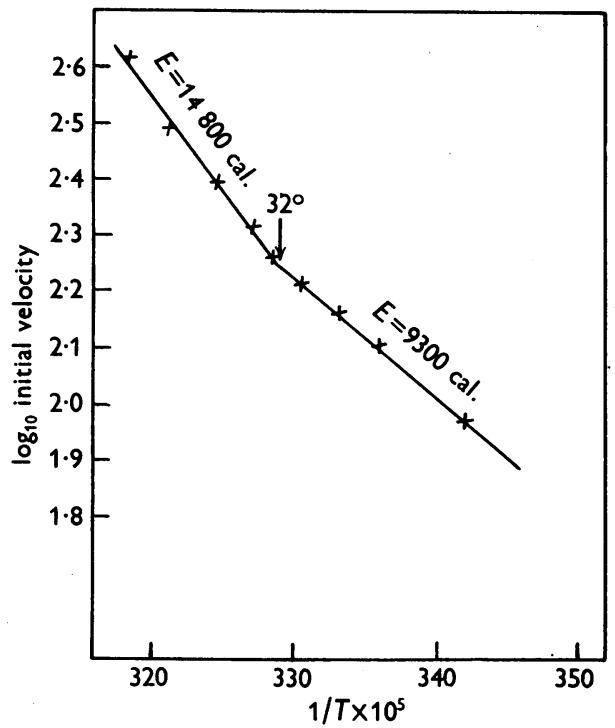

Fig. 7. The variation with temperature of the initial velocity of the dehydration reaction of fumarase in the presence of $0 \cdot 187 \mathrm{M}$-sodium borate, $\mathrm{pH} 9 \cdot 0$. Concentration of sodium L-malate, $0.033 \mathrm{M}$.

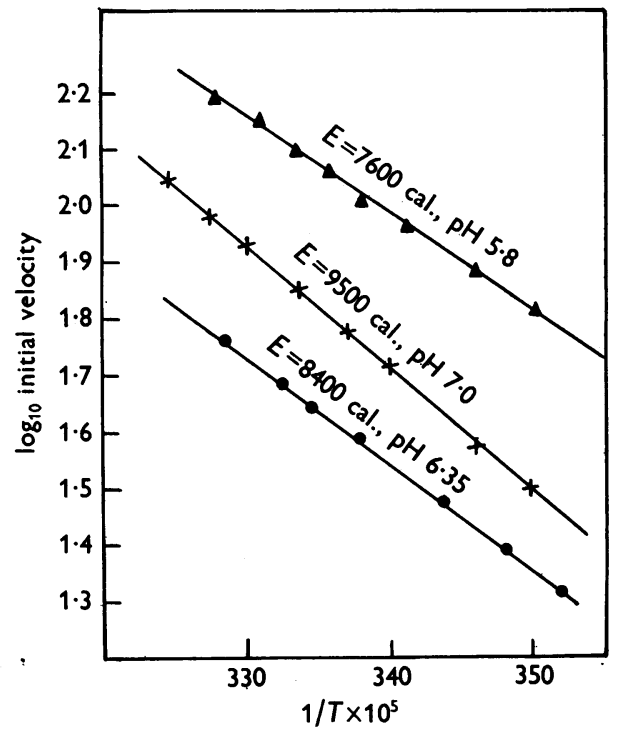

Fig. 8. The variation with temperature of the initial velocity of the hydration reaction of fumarase in the presence of $10 \%$ methanol. Sodium fumarate concentration, $0.0167 \mathrm{M}$.

apparent energy of activation. The results with methanol and ethanol are complicated by the fact that their presence causes the phosphate buffers to assume quite an appreciable temperature coefficient. Their effect is to decrease the $\mathrm{pH}$ of the buffer as the temperature is raised. As most of the results shown in Fig. 8 are at $\mathrm{pH}$ values below the optimum, the activation energies calculated from the slopes in Fig. 8 will in fact be smaller than the real values. Methanol (10\%) has a similar effect when L-malate is the substrate. For example, at $\mathrm{pH} 7 \cdot 6$ in the absence of methanol the activation energy is $13600 \mathrm{cal}$., in the presence of $10 \%$ methanol it is 14800 cal.; a correction made for change in $\mathrm{pH}$ with temperature when methanol is present would bring this value to about $16000 \mathrm{cal}$.

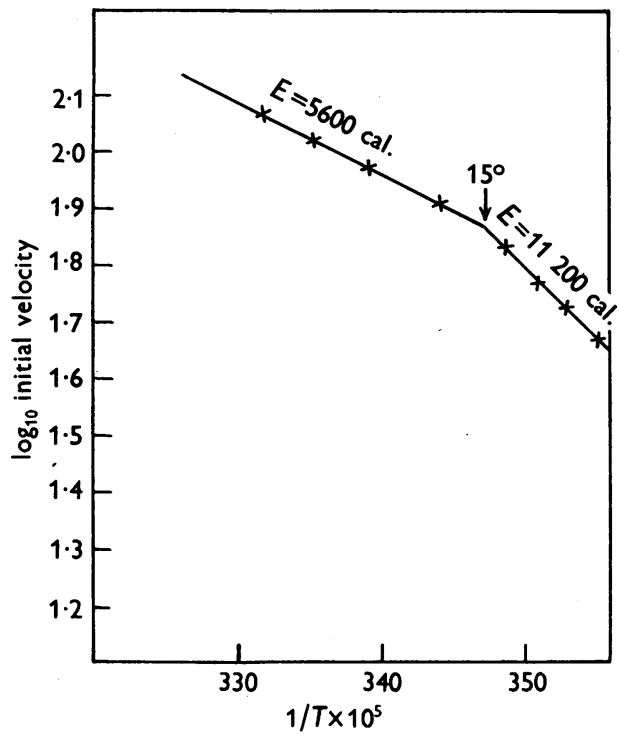

Fig. 9. The variation with temperature of the initial velocity of the hydration reaction of fumarase in the presence of $10 \%$ ethanol at $\mathrm{pH} 6.5$. Sodium fumarate concentration, $0.0167 \mathrm{M}$.

The effect of methanol cannot be due to breaking of hydrogen bonds between molecules of water, as ethanol which also reduces the hydrogen bonding has no effect in producing a single activation energy over the range of temperature studied, although its presence does appear to lower the critical temperature at which the break occurs (Fig. 9).

The ionization constants of fumaric acid. It was considered possible that the explanation for the change of activation energy at low $\mathrm{pH}$ values when fumarate is substrate might be in some anomalous property of fumaric acid, such as a sharp change in the ionization constant at $18^{\circ}$. If fumarase were to combine preferentially with one of the ionic forms of fumaric acid such a change would go a long way toward providing an explanation for this phenomenon. Accordingly, the ionization constants of twice recrystallized fumaric acid were determined 
at various temperatures by electrometric titration in an atmosphere of nitrogen. The results are shown in Table 2. There is no evidence from these results to suggest that the changes in activation energy with temperature are linked with the ionization constants of fumaric acid.

Table 2. The effect of temperature on the ionization constants of fumaric acid

$\begin{array}{ccc}\underset{\left({ }^{\circ}\right)}{\text { Temperature }} & & \\ 4 & \mathrm{pK}_{1} & \mathrm{pK}_{\mathbf{2}} \\ & \mathbf{3 . 0 2} & 4 \cdot 24 \\ 17 \cdot 5 & \mathbf{3 . 0 4} & 4 \cdot 26 \\ 32 & 3.05 & 4 \cdot 31 \\ 35 & 3.00 & 4 \cdot 30 \\ & 3.03 & 4.35\end{array}$

The effect of temperature on Michaelis constants. At a given temperature the Michaelis constants of fumarase vary with $\mathrm{pH}$ in the same way as the initial velocities. At a given $\mathrm{pH}$ the $K_{m}$ will also vary with temperature. It should be possible, by maintaining the $\mathrm{pH}$ constant, and studying the variation with temperature of maximum initial velocities, Michaelis constants and equilibrium constants, to obtain a thermodynamic picture of the enzymic reaction.

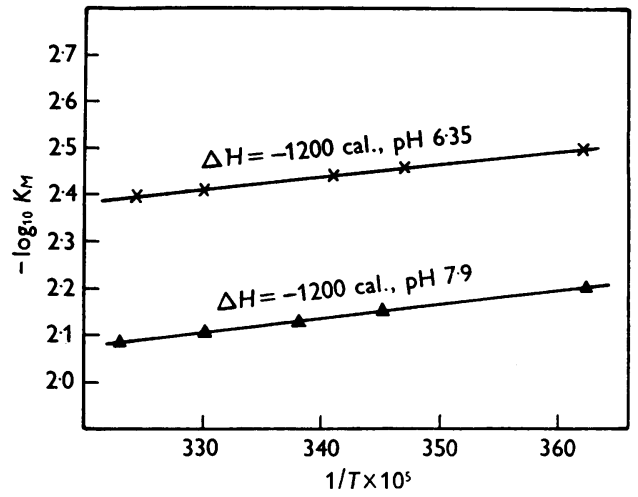

Fig. 10. The variation with temperature of the Michaelis constant of fumarase and L-malate.

Fig. 10 shows the effect of temperature on the $K_{m}$ with L-malate as substrate at $\mathrm{pH}$ 's $6 \cdot 35$ and 7.9. Here the $K_{m}$ increases as the temperature is increased, indicating that heat is evolved in the formation of the enzyme-malate complex. The $\Delta H$ value calculated from Fig. 11 is -1200 .cal./mole at both $\mathrm{pH}$ values.

Fig. 11 shows the effect of temperature on the $K_{m}$ with fumarate as substrate at $\mathrm{pH}$ 's $6 \cdot 5,6 \cdot 35$ and $7 \cdot 9$. Here, as for the initial velocities with fumarate as substrate, at low $\mathrm{pH}$ values there is a critical temperature with different heats of formation of the enzyme-substrate complex above and below this temperature. At pH 5.6 there is a break at $18^{\circ}$ with a $\Delta H$ value below this temperature of $800 \mathrm{cal} . / \mathrm{mole}$ and a $\Delta H$ value of $7100 \mathrm{cal} . / \mathrm{mole}$ above this temperature. At $\mathrm{pH} \mathrm{6.35}$ the break is again at $18^{\circ}$ and the $\Delta H$ values above and below this temperature are 4200 and 400 cal./mole respectively. At pH 8.0 the heat of formation of the Michaelis complex is $4200 \mathrm{cal}$./mole over the whole of the temperature range investigated $\left(3-35^{\circ}\right)$. It is interesting to note that whereas the formation of the fumarase-malate complex proceeds with evolution of heat, fumarasefumarate complexes absorb heat in their formation.

It is immediately striking that at low $\mathrm{pH}$ values in the presence of fumarate, the critical temperature is the same both for initial velocities and for Michaelis constants.

Also at $\mathrm{pH}$ 's $5 \cdot 6$ and $6 \cdot 35$, the differences between the $\Delta H$ values above and below the critical temperature are very similar to the difference in energy of activation $(E)$ calculated from the changes of initial velocity with temperature. Thus at pH 5.6 the difference in $\Delta H$ about the critical temperature is $6300 \mathrm{cal} . / \mathrm{mole}$ while the change in $E$ about this temperature is 5700 cal. (see Fig. 6). Similarly, at $\mathrm{pH} 6.35$ the difference in $\Delta H$ is 3800 cal./mole while the difference in $E$ is 3900 cal. At pH 8.0 there is no

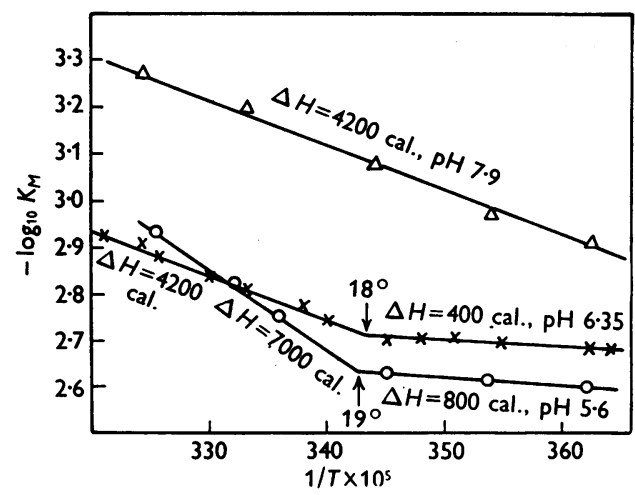

Fig. 11. The variation with temperature of the Michaelis constant of fumarase and fumarate.

change of $K_{m}$ corresponding to that found with initial velocity.

The effect of temperature on equilibrium. Fig. 12 shows the variation with temperature of the equilibrium constant $\left(K=\frac{[\text { malate }]}{\text { [fumarate }]}\right)$ at $\mathrm{pH}$ 's $6 \cdot 35$ and $7 \cdot 3$. The equilibrium is unaltered by $\mathrm{pH}$ over the range studied, and the $\Delta H$ of the overall reaction is calculated from the graph to be $3600 \mathrm{cal} . / \mathrm{mole}$. This is in good agreement with the values reported previously (Scott \& Powell, 1948; Ohlmeyer, 1945).

The heat changes of the overall reaction. The data reported give a very suggestive picture of the heat 
changes of the enzyme reaction which may throw some light on the mechanism of the reaction. The changes of initial velocity with temperature represent changes in maximum initial velocity, as the substrate concentrations used were never less

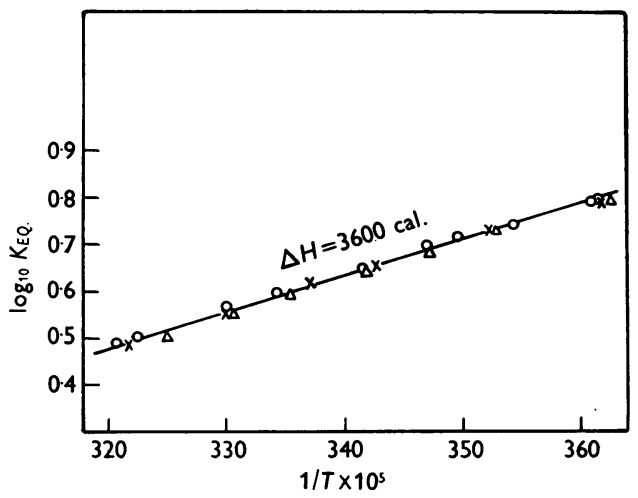

Fig. 12. The effect of temperature on the equilibrium constant $K=\frac{\text { [malate] }}{\text { [fumarate] }} . \times$, starting with sodium fumarate at $\mathrm{pH} 6 \cdot 35$; $O$, starting with sodium L-malate at $\mathrm{pH} 6.35 ; \triangle$, starting with sodium fumarate at $\mathrm{pH} 7 \cdot 3$.

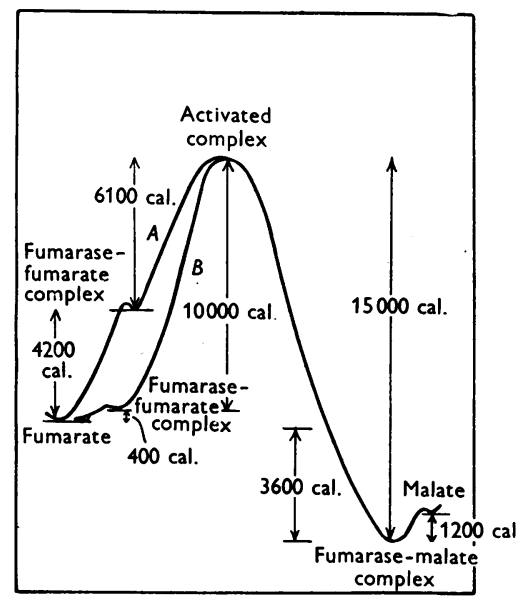

Fig. 13. A diagrammatic representation of the heat changes of the fumarase reaction at $\mathrm{pH} 6.35$. Curve $A$ represents the changes occurring above $18^{\circ}$; curve $B$ represents those occurring below $18^{\circ}$.

than five times the Michaelis constant concentration, and mostly considerably more. Hence the energy of activation values obtained from these results may be considered as due to the activation of the Michaelis complex. According to the transition state theory of Eyring \& Stearn (1939) the heat change of activation is related to the energy of activation as calculated from the Arrhenius equation in the following manner.

$$
\Delta H^{*}=E-R T \text {. }
$$

Applying this equation to the activation energy values shown in Figs. 3 and 6 we obtain a very good balance of the heat changes associated with the enzyme reaction. Thus at $\mathrm{pH} 6.35$ we have the following $\Delta H$ values. Malate has a $\Delta H$ value of 3600 cal. below fumarate. The formation of the malate-fumarase complex results in the evolution of 1200 cal. while the activation of the malatefumarase complex requires 15000 cal. This would bring the malate-fumarase activated complex to $10200 \mathrm{cal}$. above the level of fumarate. Starting with fumarate we have two temperature ranges to consider. Below the critical temperature of $18^{\circ}$ the formation of the fumarate-fumarase complex requires 400 cal. while the activation of this complex requires 10000 cal., a total of $10400 \mathrm{cal}$. At temperatures higher than $18^{\circ}, 4200 \mathrm{cal}$. are required for the formation of the fumarate-fumarase complex, and $6100 \mathrm{cal}$. for its subsequent activation, a total of $10300 \mathrm{cal}$. Fig. 13 shows diagrammatically the $\Delta H$ values for the enzyme reaction under these conditions. These results strongly suggest that the first stage of the enzymic reaction with either substrate is the formation of an enzymesubstrate complex followed by the thermal activation of this complex to an unstable intermediate activated complex.

\section{DISCUSSION}

The experiments reported here throw some light on the mechanics of the reaction brought about by fumarase, but leave many points unexplained. Thus while it is shown that the changeover from one activation energy to another around $18^{\circ}$ at low $\mathrm{pH}$ values is coupled with a corresponding and compensating change in the heat of formation of the fumarase-fumarate complex, no explanation of why this change should occur is obvious.

It is tempting to believe that such a change is associated with the orientation of water into the reaction, as it occurs only with the hydration reaction and not with the dehydration reaction. Very suggestive circumstantial evidence exists for this explanation; all the similar cases previously described, in which there is a changeover from a high activation energy to a low one as the temperature is increased, have occurred in enzymes associated with hydrolysis. Thus Sizer \& Josephson (1942) have shown that invertase, trypsin and pancreatic lipase all have a critical temperature of $0^{\circ}$, above which the activation energy is less than at temperatures below this point. They also show that under certain conditions urease has a critical temperature of $22^{\circ}$, where the same type of phenomenon occurs.

If these changes were associated with a fundamental property of water which changes at a particular temperature, then the critical temper- 
ature should be the same with all the enzymes in which this type of effect occurs. This is not so, although it might be possible to divide these enzymes into two groups, one in which the critical temperature is about $0^{\circ}$ and the other where the critical temperature is about $20^{\circ}$." Another possibility for the fumarase reaction is that the water is required in the form of its ions and at low $\mathrm{pH}$ values the concentration of hydroxyl ions might be limiting at low temperatures. However, if this were so the critical temperature should vary greatly with $\mathrm{pH}$.

It is interesting to note that the solubility of many hydrocarbons in water shows a minimum at $18^{\circ}$ (Bohon \& Claussen, 1951). It is possible that at low $\mathrm{pH}$ values the chemical structure of the enzyme-substrate complex, where the molecule of water is required for the hydration to occur, is hydrocarbon in nature.

The change from a low activation energy to a high activation energy as the temperature is increased, the phenomenon shown at high $\mathrm{pH}$ values, seems to be of a different kind from the converse reaction which we have been discussing. Here the break is obtained with both fumarate and L-malate as substrates and, unlike the type shown at low $\mathrm{pH}$ values, the critical temperature varies markedly with pH. No conclusive evidence has yet been obtained to explain this type of effect, but some preliminary experiments suggest that at high $\mathrm{pH}$ values fumarate dissociates into smaller molecular weight units as the temperature is increased. If this is so the observed effects are easily explainable if the dissociated and undissociated molecules have different temperature coefficients of activity.

This interpretation is perhaps supported by the fact that at pH 7.9 an overall picture of the enzyme reaction like that shown in Fig. 13 can be obtained at low temperatures, but not at high temperatures. Starting with fumarate at a $\Delta H$ level of 3600 cal. above malate the heat of formation of the Michaelis complex is $4200 \mathrm{cal}$. and at temperatures up to $27^{\circ}$ the heat of activation is 4300 cal., a total of $12100 \mathrm{cal}$. The heat of formation of the malateenzyme complex is -1200 cal. and the heat of activation is 12600 cal., a total of 11400 cal. At temperatures higher than $27^{\circ}$, however, the heat of activation of the enzyme-fumarate complex is $10200 \mathrm{cal}$., and all the other heat changes are the same as at lower temperatures. Thus the activated complex starting with fumarate is 18000 cal. above malate, while the activated complex starting with malate is 11400 cal. as before.

This discrepancy can be explained if the following assumptions are made. At temperatures about $27^{\circ}$ fumarase dissociates into a different molecular weight unit which has the same Michaelis constants as the undissociated molecule but a higher activation energy. The presence of substrate protects the enzyme from this dissociation, malate being a more efficient protector than fumarate.

The different effects of methanol and ethanol are difficult to explain. Perhaps methanol is capable of replacing water in the fumarase reaction, whereas ethanol owing to its larger size is not. If such a reaction were to occur then presumably the combination of alcohol and the hydrocarbon part of the enzyme or enzyme-substrate complex would not be temperature-dependent the same way as would be expected with hydrocarbon-water combination. However, there is as yet no evidence that methanol is capable of replacing water in the fumarase reaction.

The correlation between enzyme activity and $K_{m}$ with $\mathrm{pH}$ is also very difficult to explain. The correlation is not very strict, for example over the range $\mathrm{pH} 5 \cdot 6-6 \cdot 35$ the $K_{m}$ for fumarate does not change, while the activity changes considerably over the same $\mathrm{pH}$ range. Also the change of $K_{m}$ is not directly proportional to the velocity, over the remainder of the $\mathrm{pH}$ range studied, but certainly does tend to vary in the same way. This suggests that the Michaelis constant is not merely an equilibrium constant defining the relation between enzyme-substrate complex, free enzyme and substrate, but is a measure also of the rate at which the enzyme-substrate complex is converted to the free enzyme and the products of the reaction. In other words the Briggs \& Haldane (1925) modification of the theory of Michaelis \& Menten (1913) may be true at least partially for fumarase. However, the evidence presented for the change of $K_{m}$ with temperature when the $\mathrm{pH}$ is kept constant shows that there is no such correlation between $K_{m}$ and the velocity of the overall reaction as occurs with change of $\mathrm{pH}$ at a particular temperature. On the contrary, if it is assumed that the Michaelis constant is an equilibrium constant relating enzyme-substrate complex, free enzyme and substrate, only then is one justified in calculating the heat of formation of the enzyme-substrate complex from the variation of $K_{m}$ with temperature. When this assumption is made the highly convincing picture of the heat changes of overall reaction shown in Fig. 13 is obtained. One is thus left with the conclusion that one, or perhaps both, of these paradoxical sets of results is fortuitous. It seems more likely that the tendency of $K_{m}$ to vary with $\mathrm{pH}$ in the same way as the maximum velocity is the fortuitous one. There is considerable evidence (to be published later) that the combination of fumarase and substrates is largely ionic in nature. If the same ionic groups responsible for the combination of enzyme and substrate also contribute to the activation of the enzyme-substrate complex, then it follows that there will be a correlation between the value of the Michaelis constant and the velocity of the enzymic reaction, but without the Michaelis constant being dependent on the velocity. 


\section{SUMMARY}

1. The Michaelis constants of fumarase for its two substrates vary with $\mathrm{pH}$ in the same way as the initial velocities of enzyme reaction.

2. The effects of temperature on the rates of the hydration and dehydration reactions of fumarase at various $\mathrm{pH}$ values are described and activation energies are calculated. The activation energies of both reactions vary with $\mathrm{pH}$, and for the hydration reaction vary markedly with temperature. At $\mathrm{pH}$ values above the optimum, the activation energy increases at a critical temperature, which varies with the $\mathrm{pH}$, as the temperature is increased. At $\mathrm{pH}$ values around the optimum there is no variation of activation energy over the temperature range investigated. At $\mathrm{pH}$ values lower than the optimum the activation energy decreases at a critical temperature of $18^{\circ}$, which is independent of the $\mathrm{pH}$, as the temperature is increased.

3. The effect of temperature on the Michaelis constants of fumarase at various $\mathrm{pH}$ values is described, and the heats of formation of the enzymesubstrate complexes are calculated. The formation of the fumarase-malate complex is exothermic, while the formation of the fumarase-fumarate complex is endothermic. Moreover, the heats of formation of the fumarase-fumarate complex at low $\mathrm{pH}$ values change at $18^{\circ}$ in such a way as to compensate for the changes in activation energies that occur under similar conditions at this temperature.

4. The variation of equilibrium constant with temperature is described.

5. An overall picture of the heat changes associated with the action of fumarase is proposed.

6. The significance of these results is discussed.

I am greatly indebted to Dr M. Dixon, F.R.S., for designing the temperature control apparatus used in this work. I also wish to express my appreciation to Dr M. Dixon, Dr E. C. Webb, Dr G. Weber, Mr K. Gibson and the other members of the sub-department of Enzyme Biochemistry for their interest in this work and the many helpful discussions which it has involved. The work was carried out on a grant from the Commonwealth Scientific and Industrial Research Organization, Australia.

\title{
REFERENCES
}

Bohon, R. L. \& Claussen, W. F. (1951). J. Amer. chem. Soc. 73, 1571.

Briggs, G. E. \& Haldane, J. B. S. (1925). Biochem. J. 19, 338.

Britton, H. T. S. (1942). Hydrogen Ions. 3rd ed., chap. X. London: Chapman and Hall.

Eyring, H. \& Stearn, A. E. (1939). Chem. Rev. 24, 253.

Lineweaver, H. \& Burk, D. (1934). J. Amer. chem. Soc. 56, 658.
Massey, V. (1952). Biochem. J. 51, 490.

Massey, V. (1953). Biochem. J. 53, 67.

Michaelis, L. \& Menten, M. L. (1913). Biochem. Z. 49, 333.

Ohlmeyer, P. (1945). Hoppe-Seyl. Z. 282, 37.

Scott, E. M. \& Powell, R. (1948). J. Amer. Chem. Soc. 70, 1104.

Sizer, I. W. (1943). Advanc. Enzymol. 3, 35.

Sizer, I. W. \& Josephson, E. S. (1942). Food Res. 7, 201.

Stearn, A. E. (1949). Advanc. Enzymol. 9, 25.

\section{The Electrophoresis of Acid Mucopolysaccharides on Filter Paper}

\author{
By K. G. RIENITS \\ Department of Anatomy, University of Birmingham
}

(Received 25 March 1952)

Electrophoresis, using strips of filter paper as a matrix to support the buffer solutions, has frequently been used to separate individual proteins from mixtures: e.g. serum (Durrum, 1950; Cremer \& Tiselius, 1950; Wieland \& Fischer, 1948; Grassman, Hannig \& Knedel, 1951); enzymes (Wallenfels \& Pechman, 1951) and artificial mixtures of purified proteins (Kunkel \& Tiselius, 1951). Nucleotides have also been separated by means of a modification of this method (Smellie \& Davidson, 1951).

The present paper deals with the application of the method to the separation of some acid mucopolysaccharides. It was hoped that it would enable relatively small amounts of material to be examined and that it might give an indication of the amount and nature of any impurities. Blix (1940) showed that, in free solution at $\mathrm{pH} 8 \cdot 0$, hyaluronic acid from synovial fluid had an electrophoretic mobility of $-12 \mathrm{~cm} .^{2} \mathrm{~V} .^{-1} \mathrm{sec} .^{-1} \times 10^{-5}$ and that chondroitin sulphate from cartilage had a mobility of $-17 \mathrm{~cm}^{2} \mathrm{~V} .^{-1} \mathrm{sec} .^{-1} \times 10^{-5}$. According to Jorpes (1946) the mobility of heparin preparations was -17 to $-19 \mathrm{~cm} .^{2} \mathrm{~V} .{ }^{-1}$ sec. $^{-1} \times 10^{-5}$ over the $\mathrm{pH}$ range 2-8, and that of chondroitin sulphate was $-16 \mathrm{~cm}^{2} \mathrm{~V} .^{-1}$ sec. ${ }^{-1} \times 10^{-5}$. These values suggest that using electrophoretic methods chondroitin 